\title{
Reseña del libro: Ensayos de historia intelectual, de Mario Oliva Medina
}

\section{Book Review: Ensayos de historia intelectual, by Mario Oliva Medina}

\author{
Eduardo Devés-Valdés*
}

\begin{abstract}
Resumen: El libro examinado aquí tiene por temas principales la relación entre intelectuales, movimientos sociales y política. Las corrientes del anarquismo y el comunismo y su papel en la historia de las ideas costarricenses son analizadas en los ensayos que componen el libro, además de movimientos intelectuales propios, como el unionismo. El lugar de las revistas en la historia intelectual también es discutido, puesto que conforman el medio en que se desarrolla un ecosistema intelectual, y su evolución es examinada con detalle en los ensayos que presenta el texto reseñado aquí. Por último, el texto se esfuerza en destacar la relevancia de figuras intelectuales poco conocidas.
\end{abstract}

Palabras claves: élite cultural; memoria colectiva; historia de las ideas; historia intelectual; América Latina.

\begin{abstract}
The book examined here has as principal themes the relationship between intellectuals, social movements and politics. The currents of anarchism and communism and their roles in the history of Costa Rican ideas are analyzed in the essays that compose this book, in addition of local intellectual movements of their own, such as unionism. The place of journals on intellectual history is also discussed, since they compose the medium in which an intellectual ecosystem is developed, and its evolution is examined in detail in the essays that are present in the text reviewed here. Lastly, the text strives in standing out the relevance of lesser-known intellectual figures.
\end{abstract}

Keywords: cultural elite; collective memory; history of ideas; intellectual history; Latin America.

Chileno. Doctor en Filosofía por la Universidad Católica de Lovaina (UCLouvain), Bélgica. Doctor en Estudios Latinoamericanos por la Universidad Sorbona Nueva, París III, Francia. Profesor del Doctorado en Estudios Americanos y de la Maestría en Estudios Internacionales de la Universidad de Santiago de Chile (Usach), Chile. Investigador del Instituro de Estudios Avanzados (IDEA), Usach, Chile. Correo electrónico: eduardo.deves@usach.cl. 
1 libro de Mario Oliva Medina Ensayos de historia intelectual ${ }^{1}$ se divide en 4 partes: 1) Intelectuales obras y quehaceres, 2) Exilios, 3) Intelectuales y movimientos sociales y 4) Trincheras de ideas. El volumen se inicia con una «Nota aclaratoria», donde el autor formula varias consideraciones acerca del carácter de esta obra que compila trabajos escritos durante la última década y que él piensa pueden agruparse bajo el rótulo de historia intelectual. Luego vienen dos prólogos de figuras muy relevantes en los estudios del pensamiento suramericano, uno de Ricardo Melgar: «Umbrales de la intelectualidad transfronteriza» ${ }^{2}$ y otro de Liliana Weinberg: «Itinerarios de amistad intelectual», ${ }^{3}$ que por varias razones fungirían mejor que estas palabras como reseñas del libro.

A riesgo de no hacer exactamente una reseña, que es lo solicitado por la revista, quiero formular, a propósito de la lectura, tres puntos de interés sobre los cuales creo poder decir algo, y por cierto, puede haber muchos otros, a partir de los cuales desatar reflexiones, que por una parte lo muestren y, por otra, incentiven lecturas y diálogos con este.

Un primer tema que quiero poner en el tapete a propósito del libro de Oliva Medina y que lo cruza de punta a cabo, es el de la articulación entre ideas e intelectualidades, por una parte la política y los movimientos sociales por otra. Dos cuestiones permanentemente asociadas, aunque muchas veces con diferencias y tensiones. En este libro, se ocupa del anarquismo y del comunismo, como agrupaciones y tendencias, pero también de otras más propiamente costarricenses, como el unionismo centroamericano. La relación entre intelectualidad y cultura pasa, casi siempre, por una institucionalidad que conecta, agrupa, y que se juega de modo algo diferente en los diversos ecosistemas intelectuales a lo largo del tiempo: revistas, editoras, organismos públicos, partidos, y universidades, entre otros.

Ocuparse de esto es una de las maneras de describir los ecosistemas intelectuales de los cuales forman parte las figuras y en medio de los cuales desarrollan su actividad. Un ecosistema intelectual como San José-Heredia y localidades inmediatas es el que da lugar a la obra de Oliva Medina en gran parte, tanto lo que es el propio autor, como los trabajos que reúne en su libro.

Mario, chileno y puertomonttino de origen, ha desarrollado toda su carrera académica en este ecosistema intelectual ya casi por 50 años. Como tantos ecosistemas intelectuales, este va elaborando relatos sobre sí mismo y este libro es una contribución a ello. Debe notarse que no es el objetivo que el autor se propuso como principal, aunque se encuentra implícito en varios de los temas que está tratando y se subentiende que está destinado al mismo ecosistema, por ello,

\footnotetext{
1 Mario Oliva Medina, Ensayos de historia intelectual (CIALC-UNAM, EUNA-UNA, 2018).

2 Ibíd.,13.

3 Ibíd.,19.
} 
no se siente obligado a dar explicaciones sobre personas y acontecimientos que suponen grosso modo conocidos.

Un segundo asunto por relevar y discutir a propósito del libro es el de las revistas. Si se habla de un ecosistema intelectual contemporáneo, es casi imposible no hablar de las publicaciones. En este volumen Oliva Medina se ocupa específicamente de dos revistas: Liberación ${ }^{4}$ y Renovación ${ }^{5}$ sin dejar de mencionar varias otras, por cierto, su predilecta: Repertorio Americano. El autor conecta estos medios con figuras intelectuales como Vicente Sáenz en primer lugar, pero también varias otras de Costa Rica, de Centroamérica y más allá. Las revistas muestran redes y afinidades intelectuales y ciertamente, su estudio es una de las vías para adentrarse en las redes que articulan la intelectualidad del momento. Uno de los factores clave para estudiar la existencia de redes consiste en determinar quienes publicaban en los mismos medios o muy cercanos y el autor aprovecha bien este recurso.

Debe decirse, sin embargo, que este método ha conducido a errores a personas con insuficiente cuidado, y no es el caso de Oliva Medina. El estudio de quienes publican en un medio es una vía para determinar la pertenencia a una red, pero es solo una de estas y para nada puede considerarse exclusiva, ni la publicación de trabajos en un mismo medio considerarse indicador indiscutible de pertenencia a una red.

Debe recordarse que, en aquellos años — las primeras décadas del XX一, las revistas no debían necesariamente, solicitar permiso de publicación para los artículos, que normalmente, se suponían de libre circulación y que ciertamente, no estaban sometidos a los derechos de autoría, como se ha venido instalando posteriormente, con las ventajas y las desventajas que ello puede traer, y mucho menos las imágenes y las fotografías que se reproducían.

Si bien en las revistas de opinión suelen publicar trabajos de personas que se encuentran en redes, se publicó a muchas otras que eran admiradas por el núcleo que editaba, así como también, se reproducían trabajos que atraerían el interés de potenciales lectores. Por otra parte, en muchas ocasiones se publicaban trabajos de autores fallecidos o traducidos y que obviamente, no tuvieron contacto personal con quienes editaban tales revistas y para nada estuvieron conectados por redes con tales editores. Con esto no pretendo insinuar que Oliva Medina confunda red con autores de artículos reproducidos en revistas, sino alertar a quienes realizan este tipo de investigaciones sobre la necesidad de cotejar con otras informaciones la pertenencia de autores a una red articulada en torno a la revista o de la cual la revista sería un medio de expresión.

Un tercer asunto y muy polémico que deseo poner en relieve es que Oliva Medina parece atribuir a varios autores relativamente poco conocidos en nuestro

4 Ibíd., 245.

5 Ibíd., 287. 
medio, aunque de obra ya antigua, algunos descubrimientos e impulsos. Por ejemplo, en su estudio de la poesía obrera destaca que sería la lectura de François Dosse $^{6}$ que le habría motivado. Mario resta mérito a su propio trabajo atribuyendo a esta inspiración, un tipo de quehacer que se cultiva con mucha antelación a la obra de Dosse y al conocimiento de esta entre nosotros. Algo parecido ocurre con lo que señala respecto de J. G. A. Pocock, ${ }^{7}$ citándolo al momento de ocuparse de información biográfica de Vicente Sáenz y la preocupación de este por la opinión de sus lectores.

No pretendo discutir sobre la validez o no de la obra de tales figuras, sino señalar que el autor no necesitaba recurrir a ellos para llevar a cabo el trabajo que ha realizado, pues su propio quehacer se enmarca en una larga trayectoria de los estudios sobre las ideas y las intelectualidades que no debe nada a estos autores y que me inclino a considerar como una excesiva modestia, pues una persona de la edad y la trayectoria de Oliva Medina no necesita validarse citando a un par de autoridades para darle lustre a su trabajo, como sería quizás una buena razón para gente que se inicia en estos temas y que quiere cuidarse los flancos, poniendo algunos grandes nombres como guardaespaldas, que le protegerían de críticas por carencias. Tampoco, se trata de mostrar que nos hemos adelantado en la región a la obra de Pocock, de Dosse o de R. Chartier, ${ }^{8}$ de ningún modo, simplemente llamar la atención sobre que nuestro quehacer ha sido notoriamente más amplio, variado y sofisticado de lo que nos damos cuenta a simple vista y que tiene poco sentido la recurrencia a tales o cuales autores para poner en relieve algunas innovaciones.

Prueba, por otra parte, de la autonomía intelectual del autor y de su no adscripción a la agenda de la historia intelectual es que si su libro lleva en el título la identificación con esta subdisciplina, la mayoría de los trabajos incluidos no corresponden a las indicaciones de los popes, como tampoco los cita en dichos trabajos, ni aparecen en la bibliografía. O quizás Oliva Medina ha innovado en sus propios quehaceres a partir de su familiarización con estos autores, reformulando su agenda de trabajo, como lo señalan ambos prologuistas desde la historia social a la historia intelectual. ${ }^{9}$

\section{Bibliografía}

Oliva Medina, Mario. Ensayos de historia intelectual. CIALC-UNAM, EUNA-UNA, 2018.

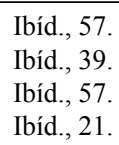

